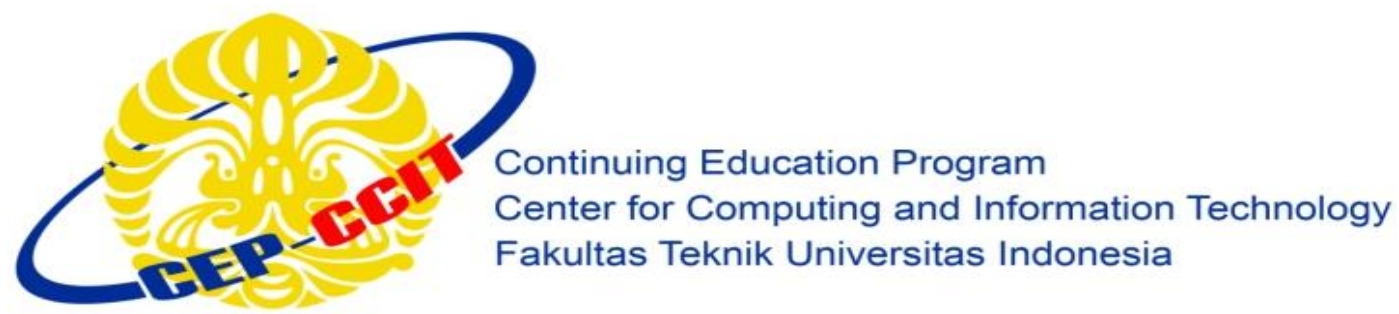

PROJECT

\title{
CONFIGURATION SAMBA SERVER FILE SHARING
}

$\begin{array}{llll}\text { Arranged by } & : & \text { 1. Rio Ramadhan } & 1610010186 \\ & & \text { 2. Rizki Amalia } & 1610010188 \\ \text { Class } & : & 4 N A P 1 \\ \text { Faculty } & : & \text { Tri Agus Riyadi, MT } \\ \text { Semester } & : & 4\end{array}$

Continuing Education Program Center for Computing and Information Technology

Faculty of Engineering, University of Indonesia 


\section{Project ON \\ CONFIGURATION SAMBA SERVER FILE SHARING}

\section{Developed By}

Name : Rio Ramadhan

Rizki Amalia

Faculty $\quad: \quad$ Tri Agus Riyadi, MT
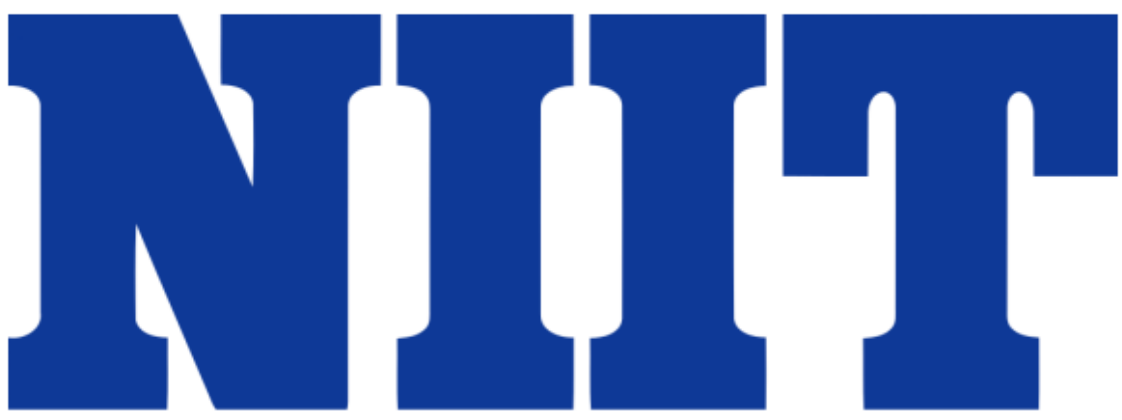

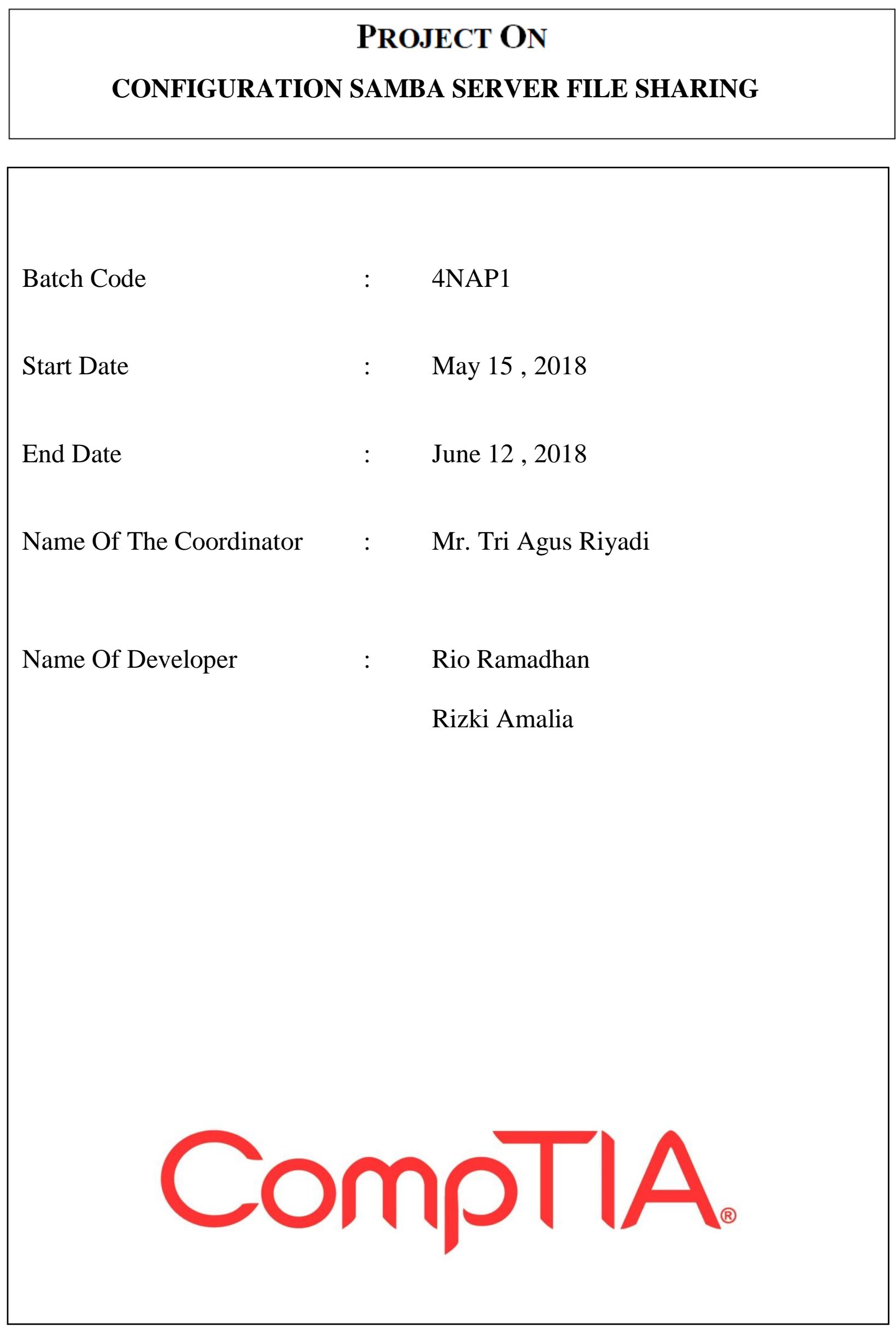


\section{CERTIFICATE}

This is to certify that this report titled CONFIG SAMBA SERVER FILE SHARING embodies the original work done by Rio Ramadhan and Rizki Amalia in partial fulfillment of their course requirement at NIIT.

Coordinator:

Mr. Tri Agus Riyadi

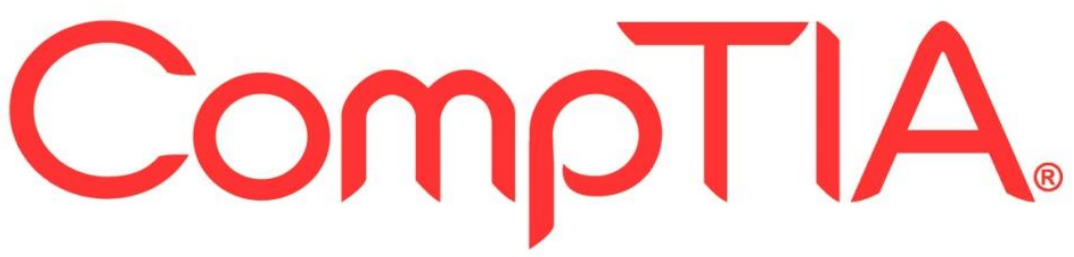




\section{ACKNOWLEDGEMENT}

First of all, the authors pray gratitude for the presence of God because of favors and gifts the authors can complete the Project. On this occasion the authors would like to say thanks the Mr. Tri Agus Riyad, S. Kom, MT and other faculty members who always guide the authors so this project finish properly and on time. And also the authors say many thanks to those who have supported in process making this project. Also thanks to reader application users at the same time. The Authors hope this project can be beneficial.

Depok, May 2018

Authors 


\section{INTRODUCTION}

Samba is an application that enables a network administrator to work in an open environment with full flexibility and freedom in terms of configuration, setups and other selection regarding hardware and system elements. In other words, Samba was designed to remove hurdles to interoperability.

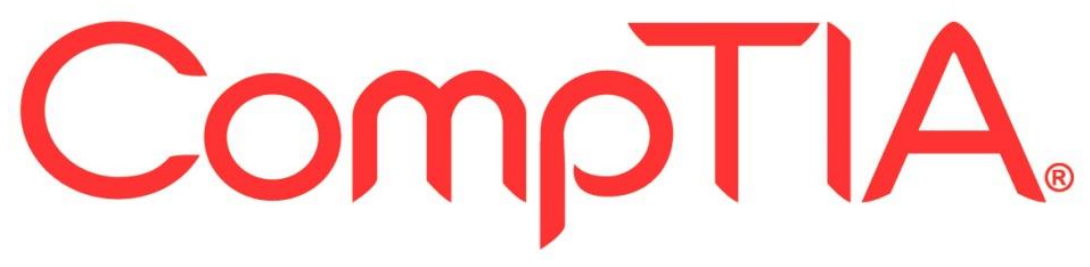




\section{IN GENERAL STEPS}

The following task have been performed to meet the specification of the project scenario :

1. Make directory with mkdir public_share and chmod 777 public_share.

2. Make directory with mkdir admin and chmod 777 admin.

3. Then, sign in sudo su and apt-get install samba for installing samba.

4. Fourth, locate smb.conf.

5. Fifth, gedit /etc/samba/smb.conf for modify directive settings as described below and save.

6. Then, writte useradd admin.

7. And, addgroup private.

8. Usermod $-\mathrm{a}-\mathrm{G}$ private admin, only admin change a user's system account settings.

9. Smbpasswd -a admin.

10. Chownadmin : private admin.

11. Sudo service samba restart.

12. Open up cmd and edit file path.

13. Making a folder in public_share and admin.

14. Folder penting and data admin has been exist.

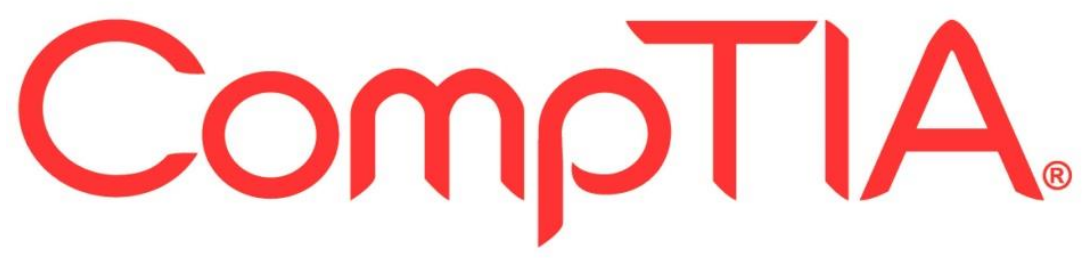




\section{STEP-STEP CONFIGURATION SAMBA SERVER FILE SHARING}

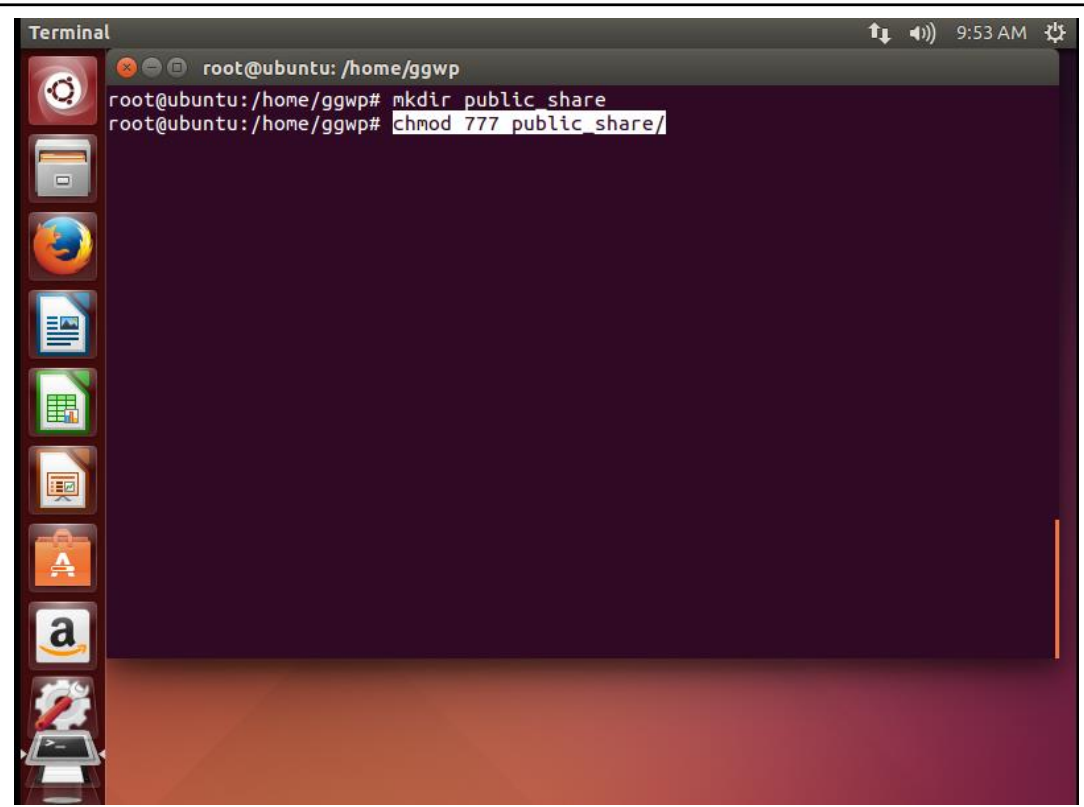

First start by creating a shared samba directory name public_share. Then set the appropriate permissions on the directory. This will give permissions to all files currently in the folder and files added in the future without giving permissions to the directory itself.

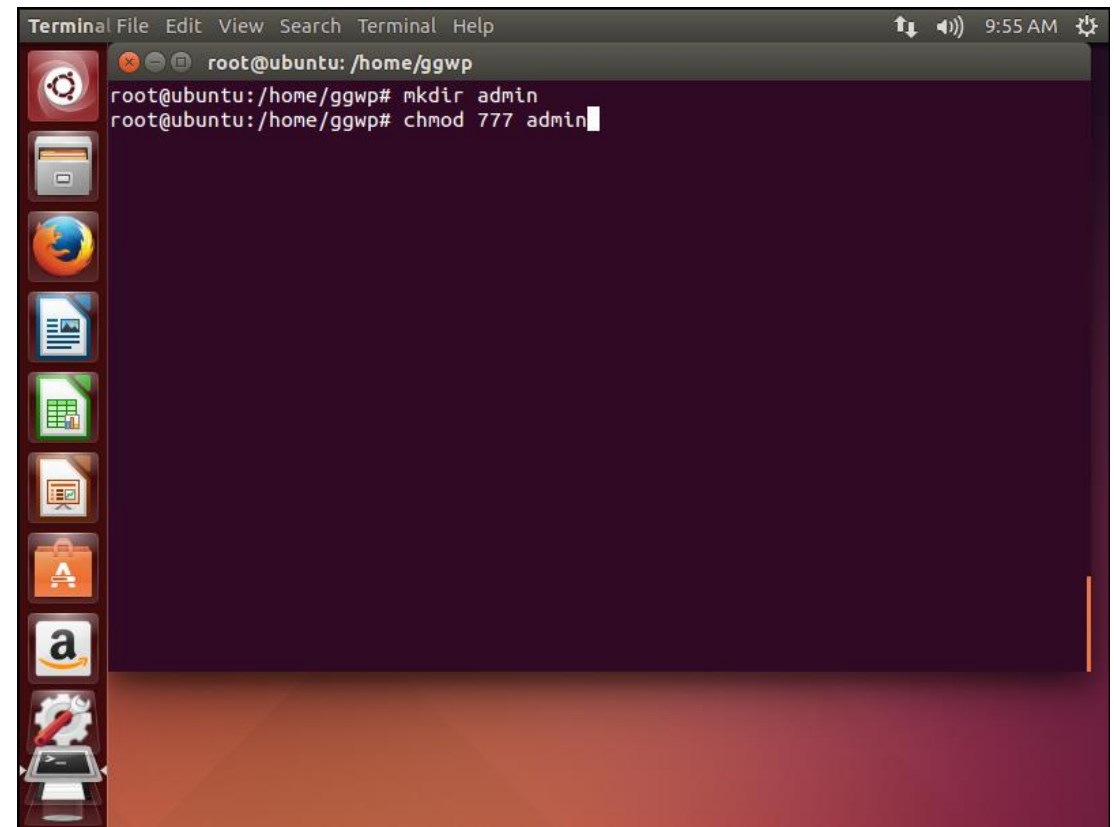

Then creating a shared samba directory name admin. Then set the appropriate permissions on the directory. This will give permissions to all files currently in the folder and files added in the future giving permissions to admin only. 


\section{STEP-STEP CONFIGURATION SAMBA SERVER FILE SHARING}

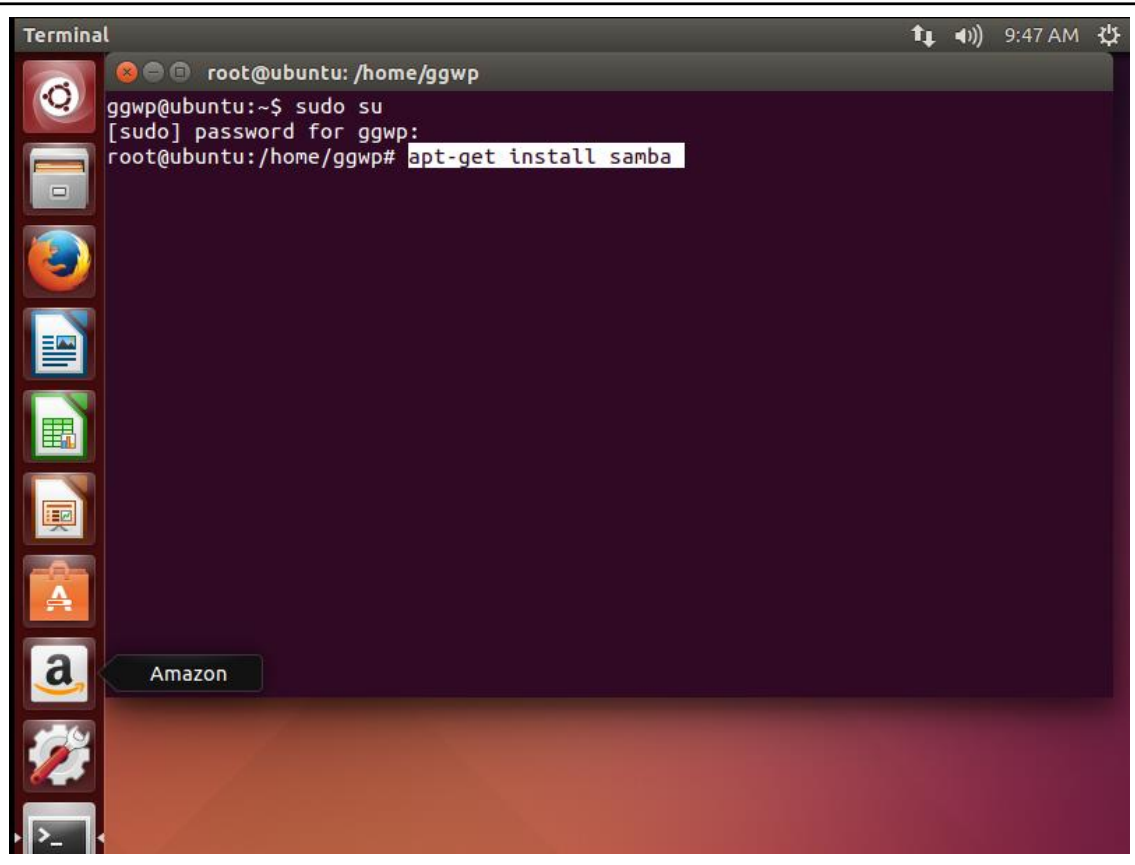

Entered into root, then installing samba with apt-get install samba

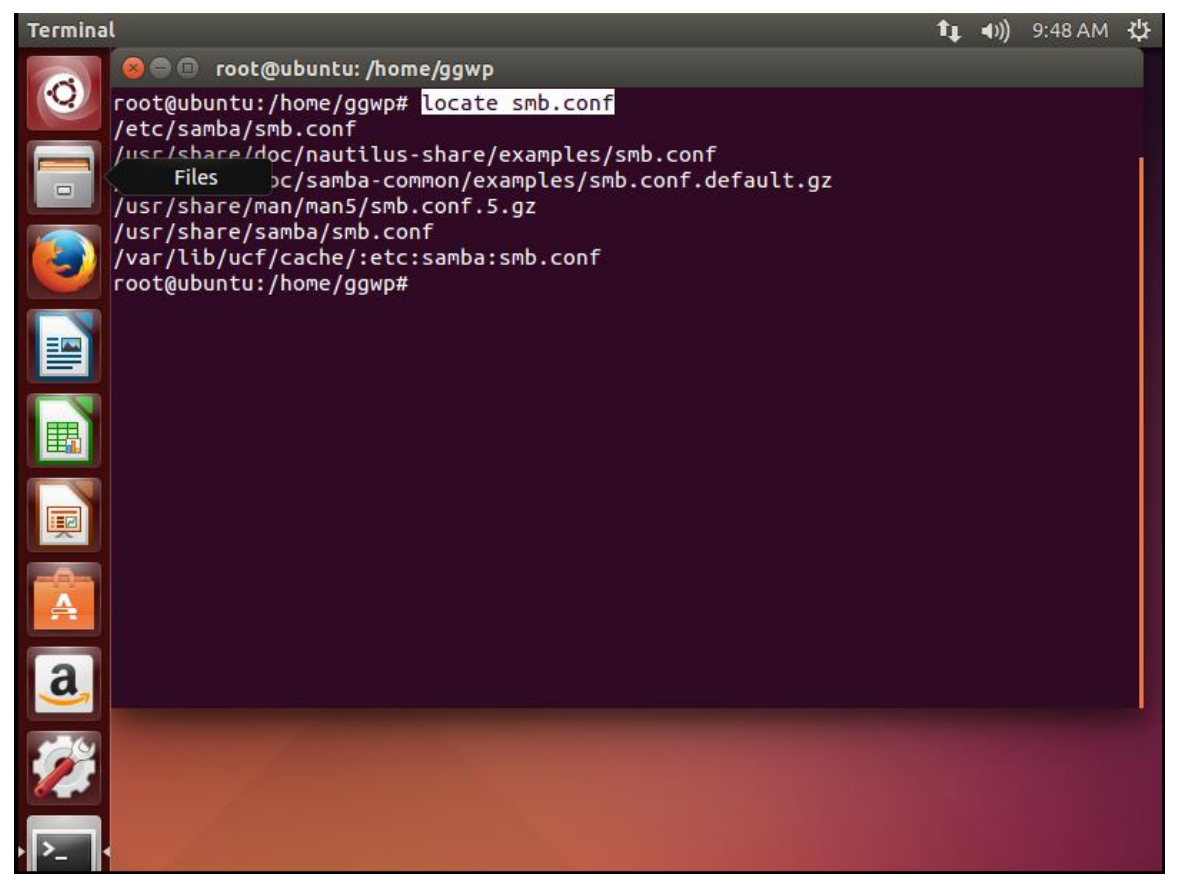

We can find if the installation was successful by running locate smb.conf 


\section{STEP-STEP CONFIGURATION SAMBA SERVER FILE SHARING}

Now open the configuration file : gedit/etc/samba/smb.conf

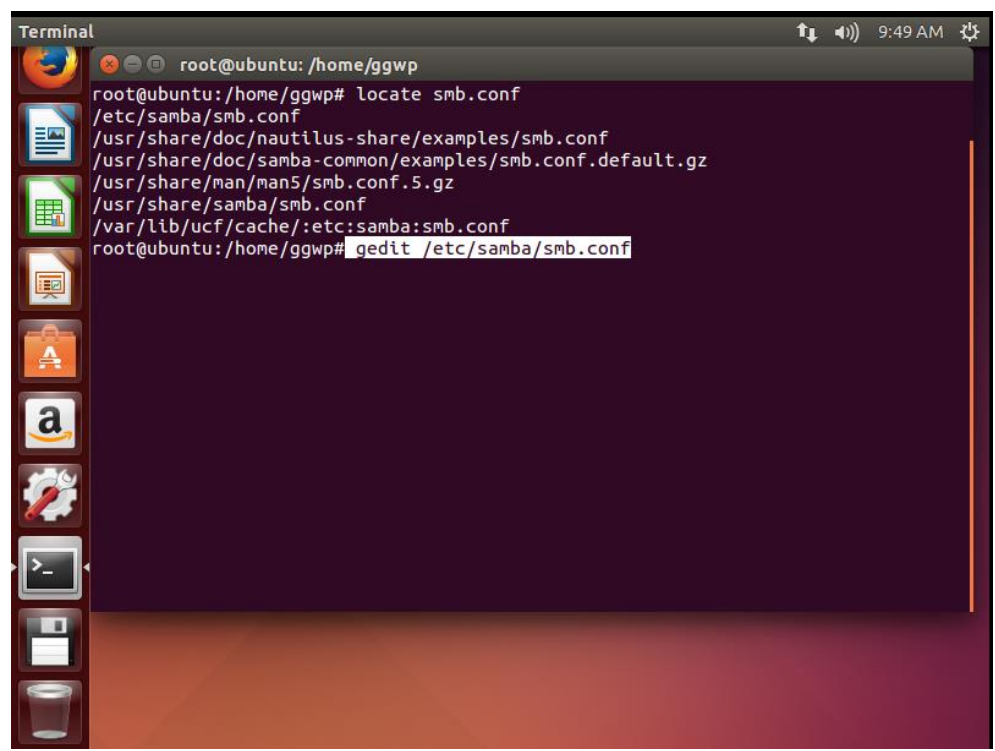

Next edit or modify the directive settings as described below.

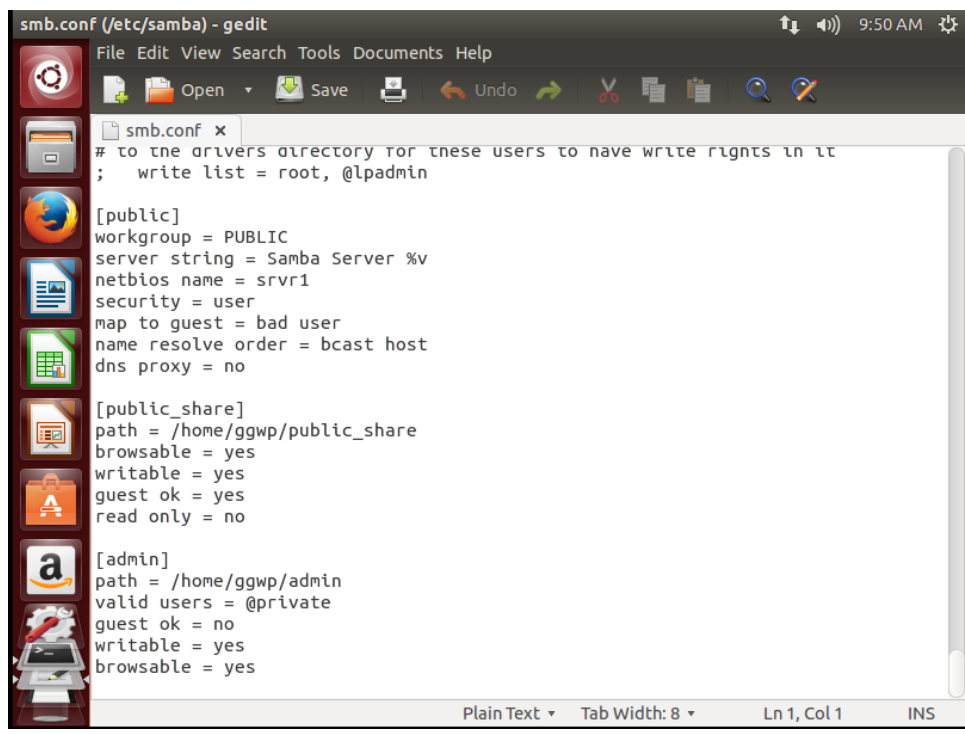

Then press Ctrl-O to save and Ctrl-X to exit from the gedit text editor 


\section{STEP-STEP CONFIGURATION SAMBA SERVER FILE SHARING}

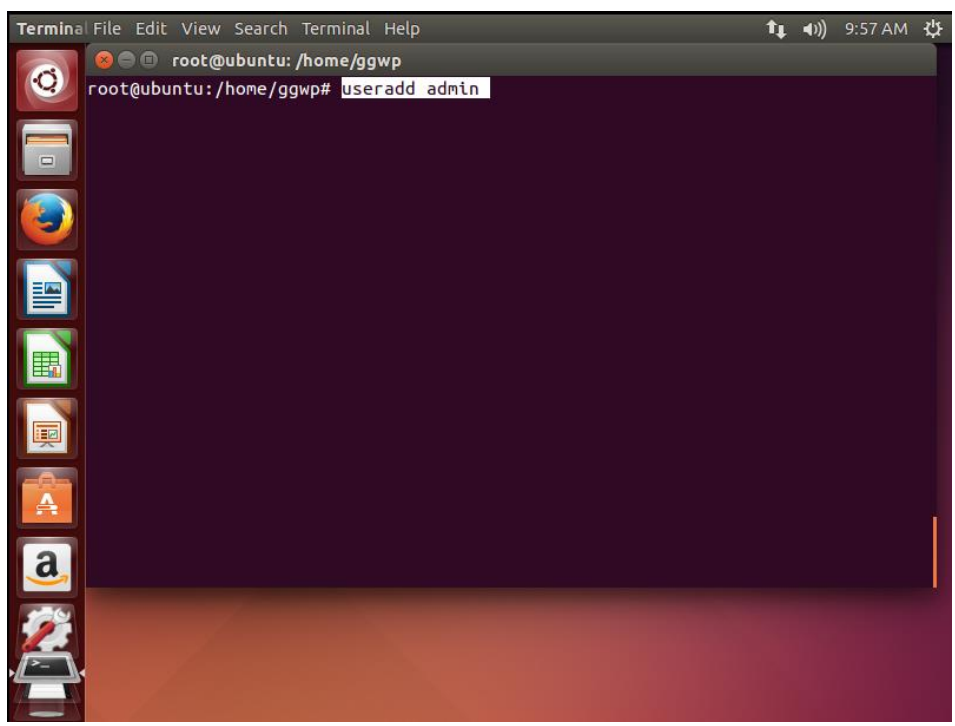

Adding the admin by useradd admin

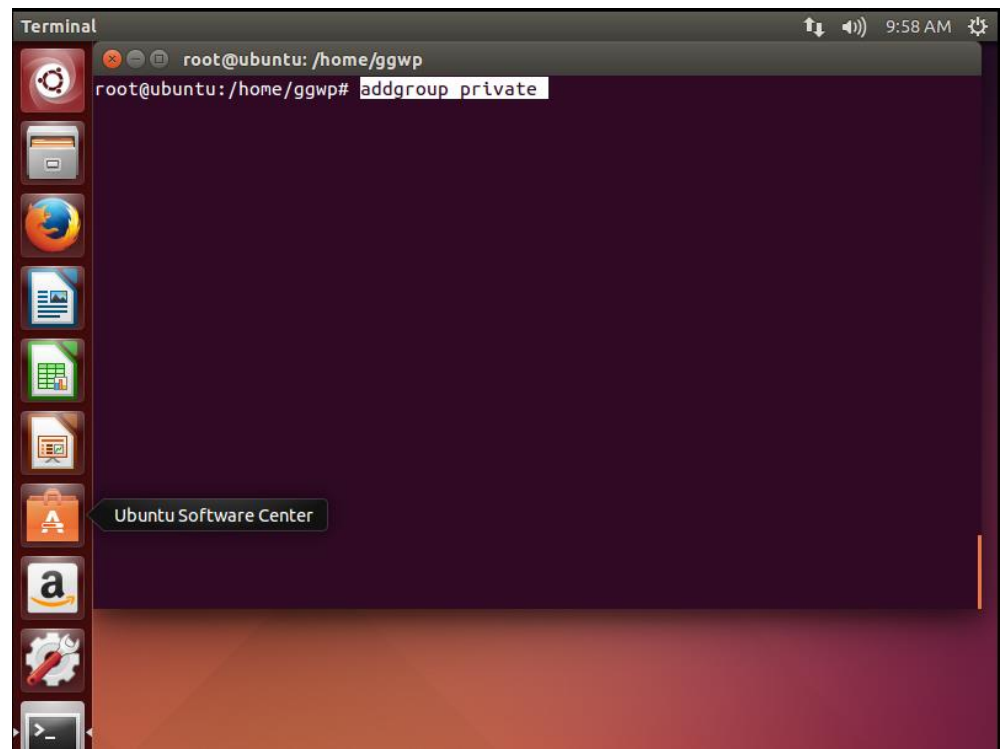

Added a group private only admin able to access 


\section{STEP-STEP CONFIGURATION SAMBA SERVER FILE SHARING}

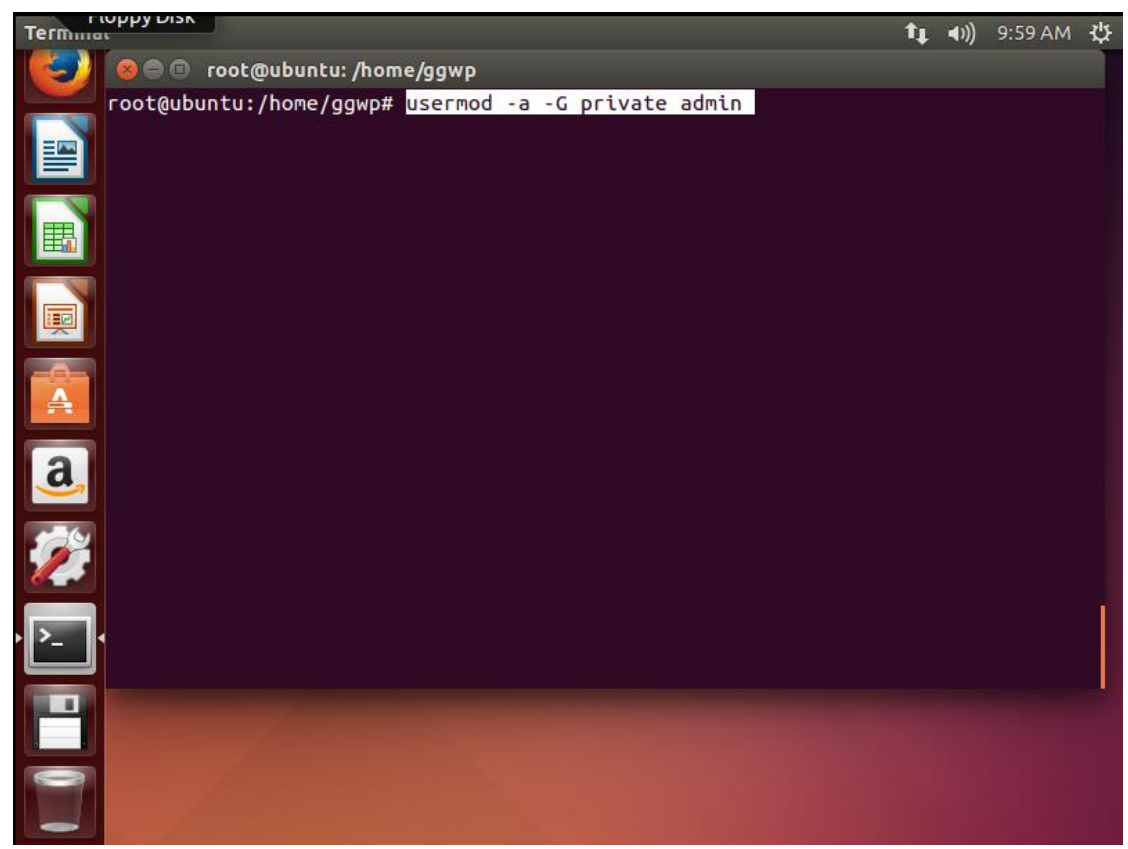

Only admin change a user's system account settings.

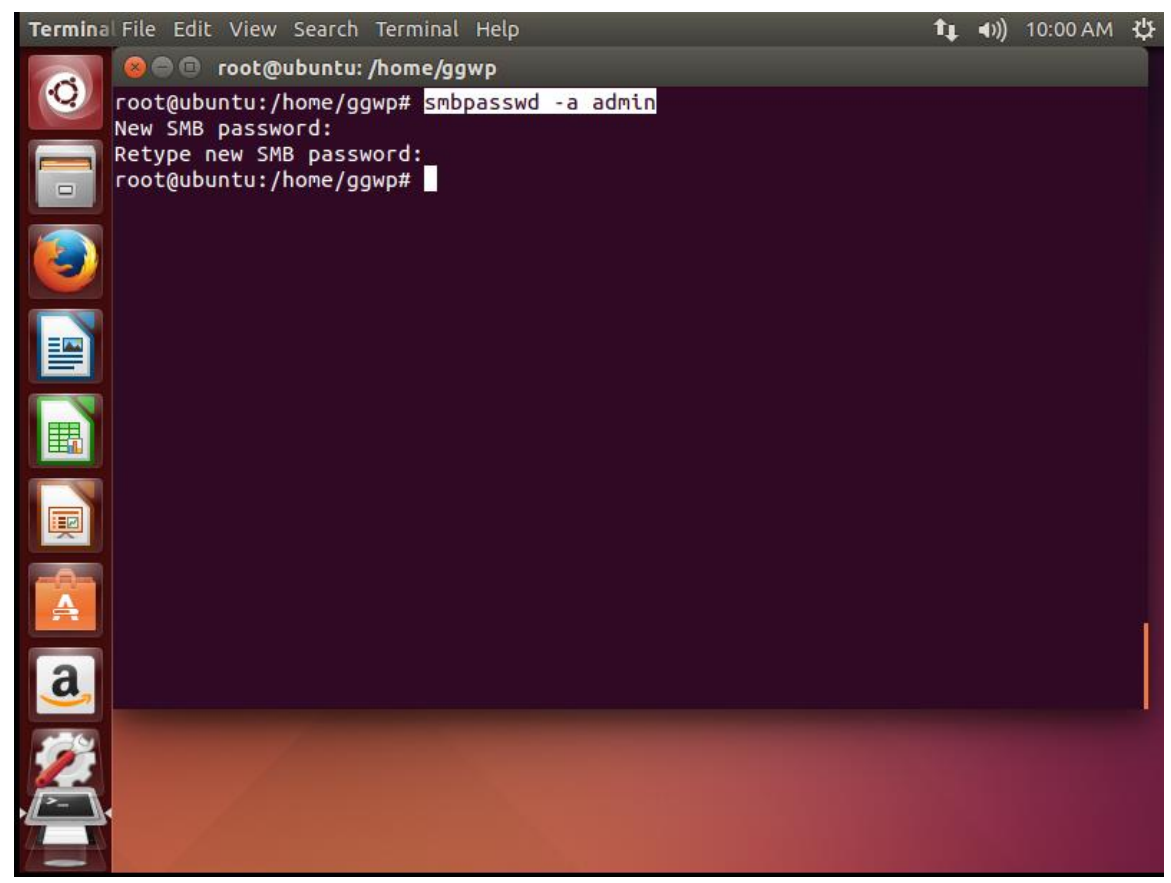

Admin set the encrypted password used by samba server 


\section{STEP-STEP CONFIGURATION SAMBA SERVER FILE SHARING}

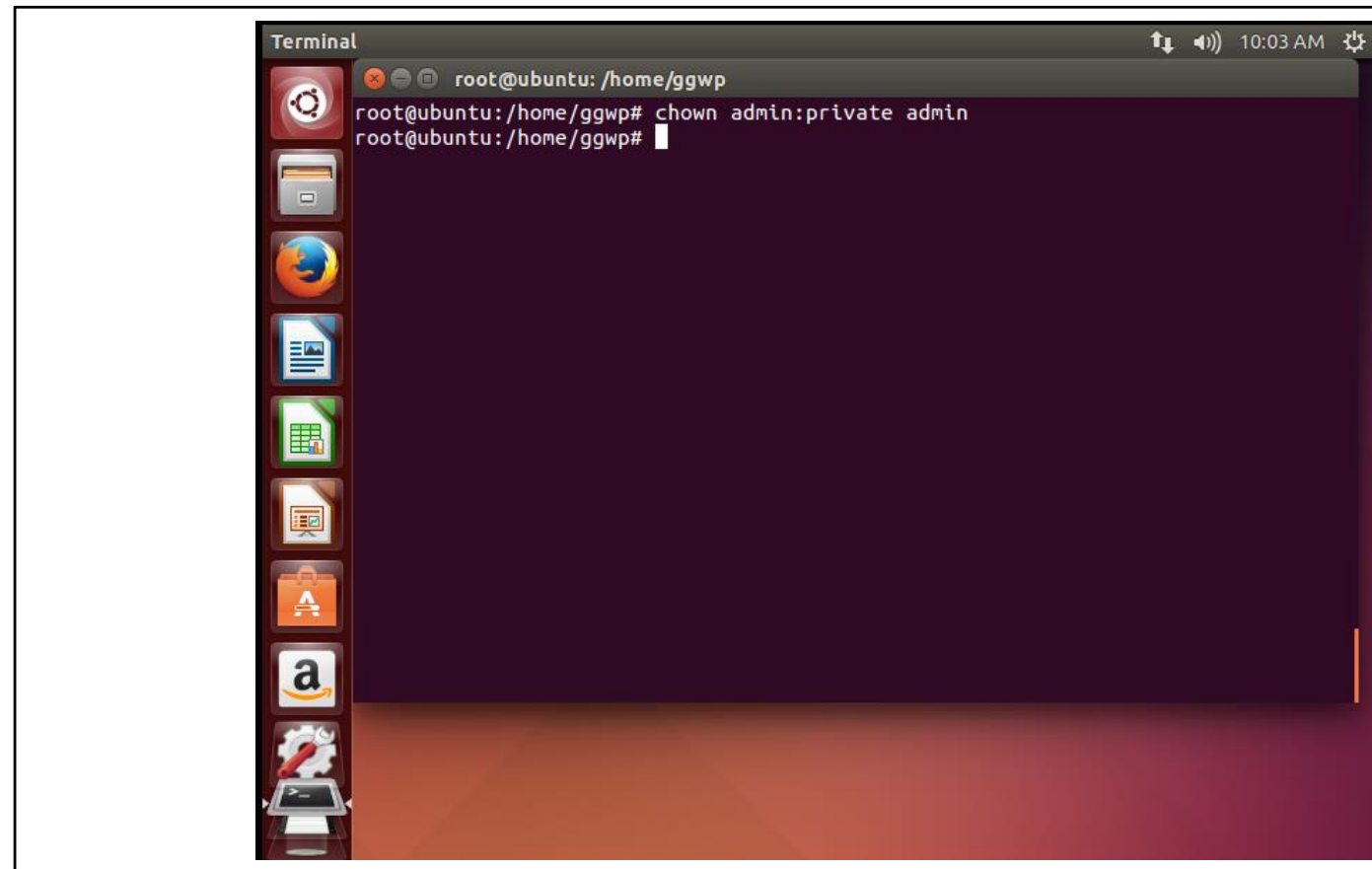

Admin can change owner file.

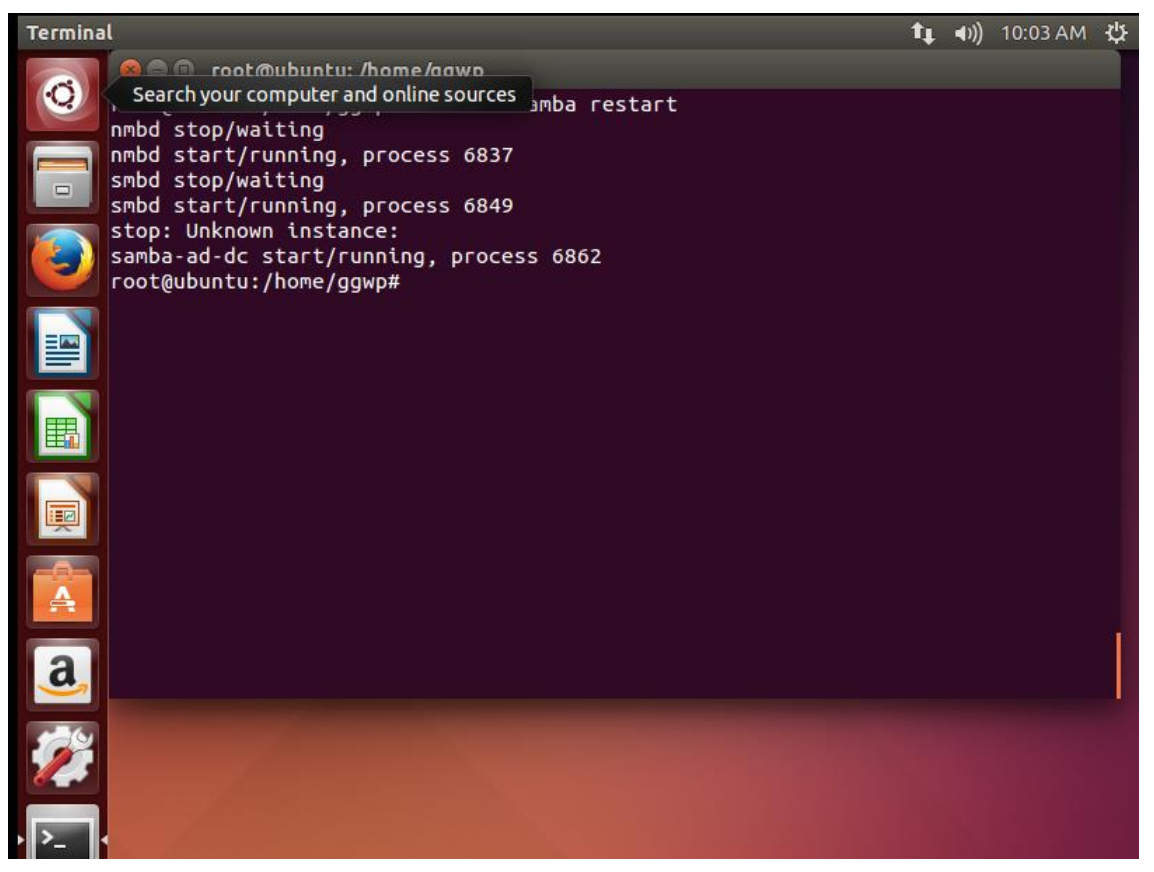

Now that we have our new share configured, save it and restart Samba for it to take effect. 


\section{STEP-STEP CONFIGURATION SAMBA SERVER FILE SHARING}

On Windows, open up cmd and edit the file path to:

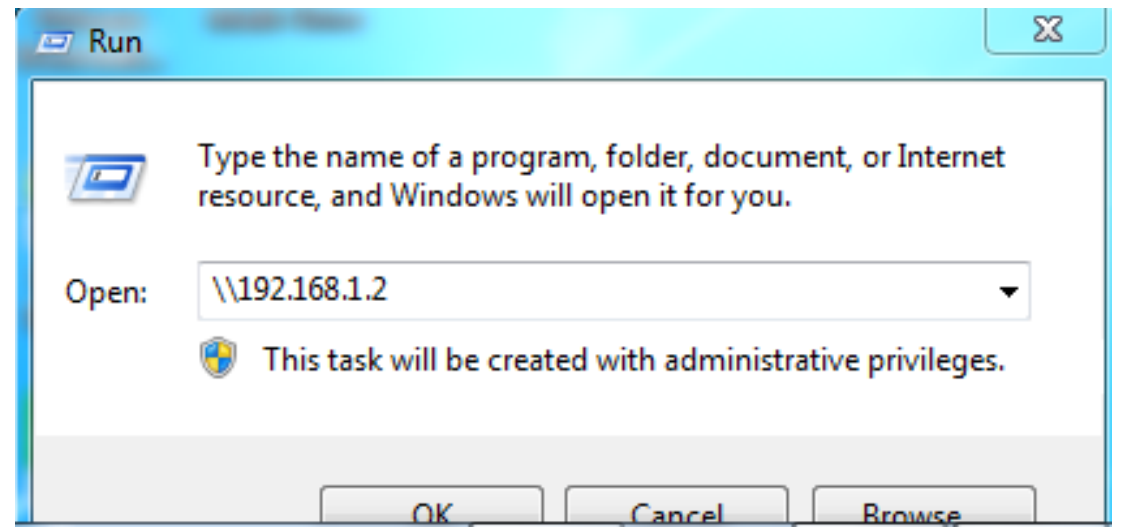

Between Ubuntu and windows now is connected.

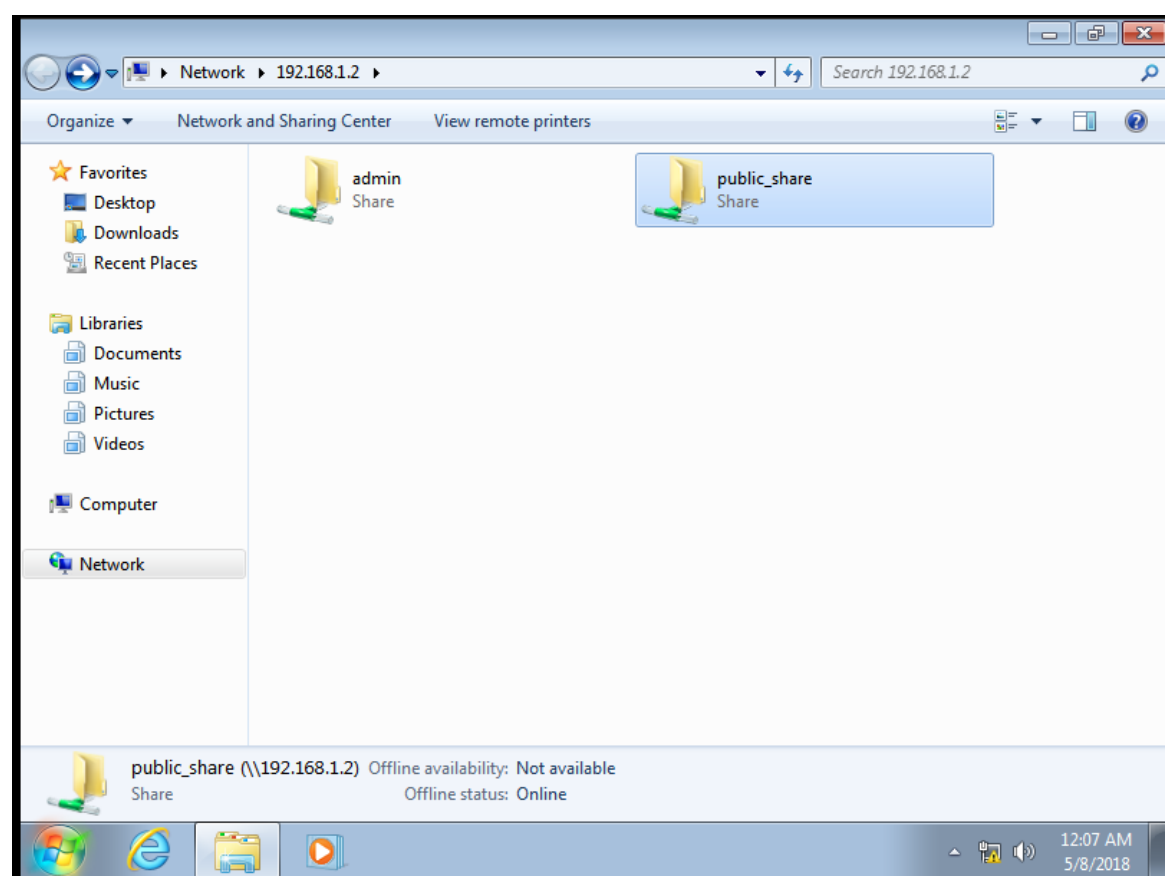




\section{STEP-STEP CONFIGURATION SAMBA SERVER FILE SHARING}

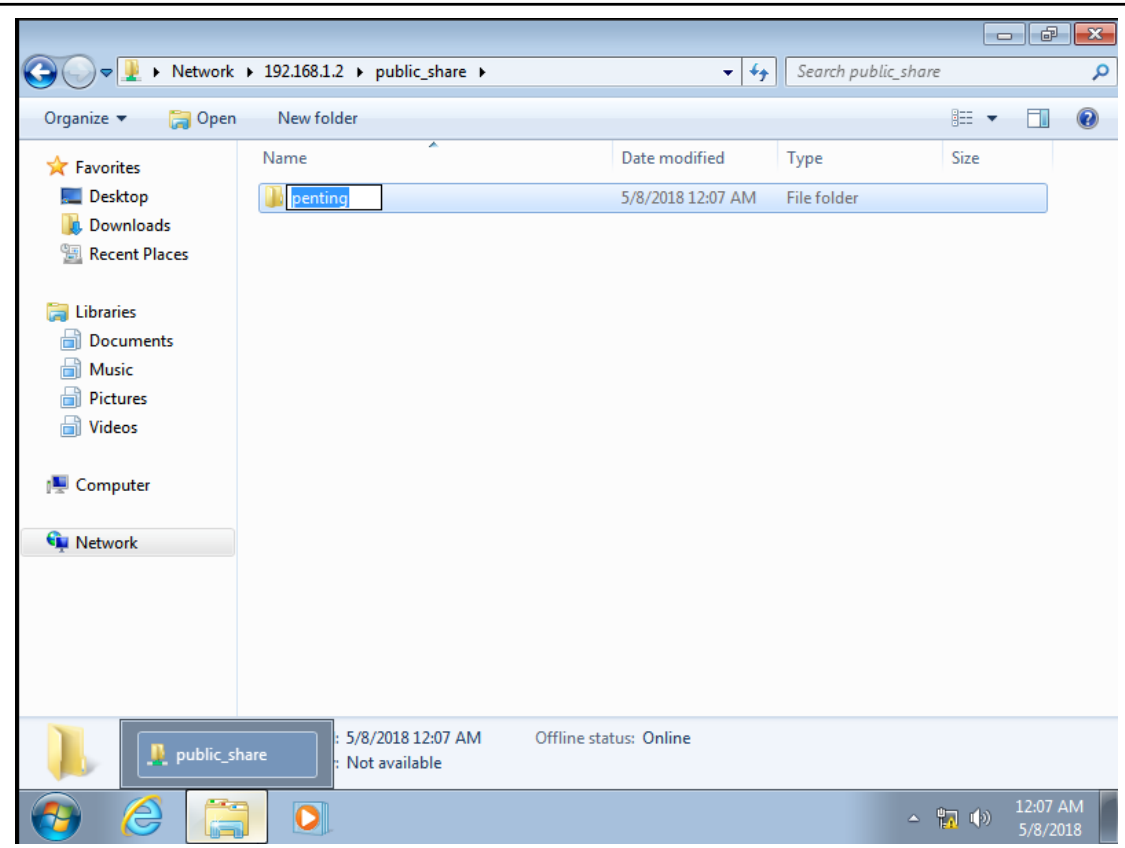

Making a folder sharing in public_share.

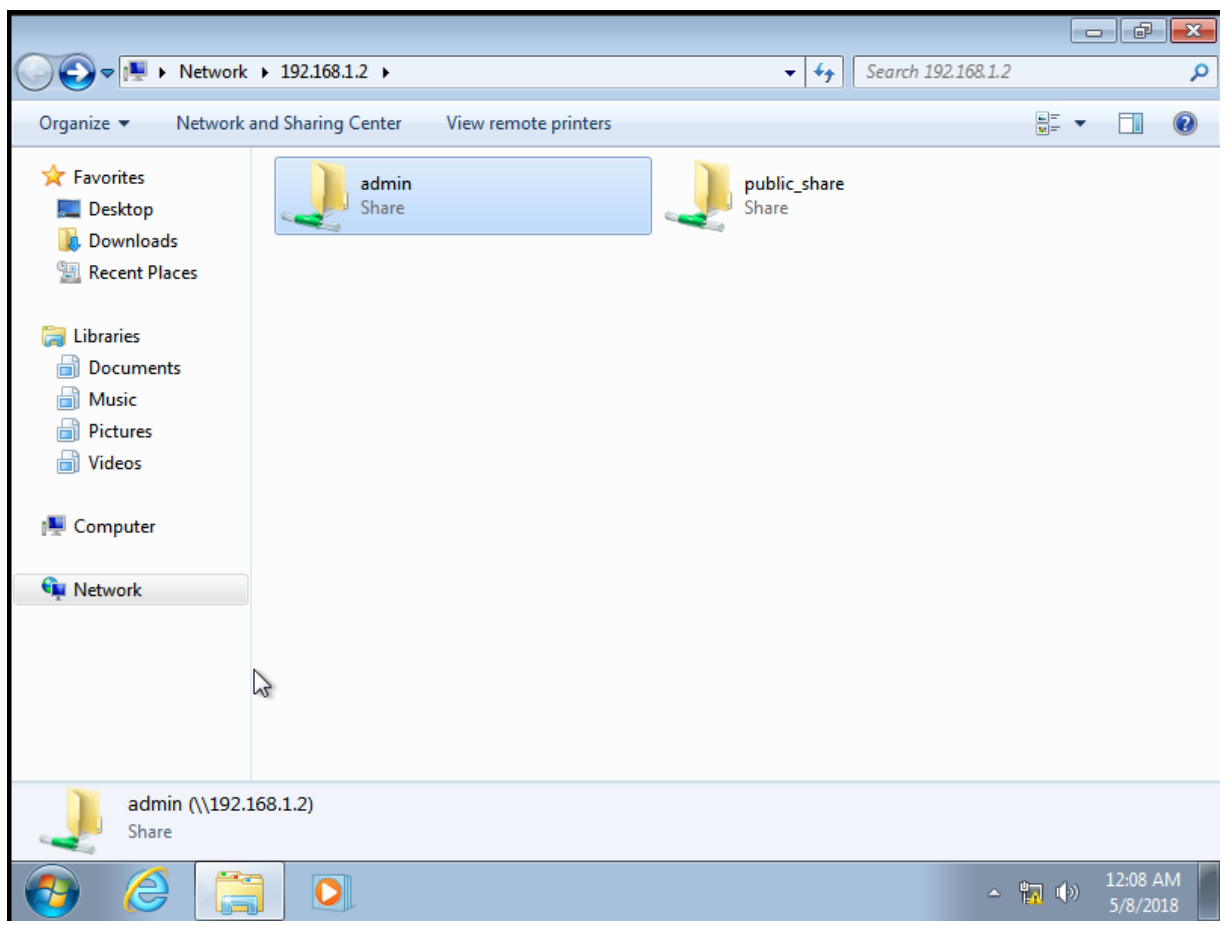

Click the admin file sharing 


\section{STEP-STEP CONFIGURATION SAMBA SERVER FILE SHARING}

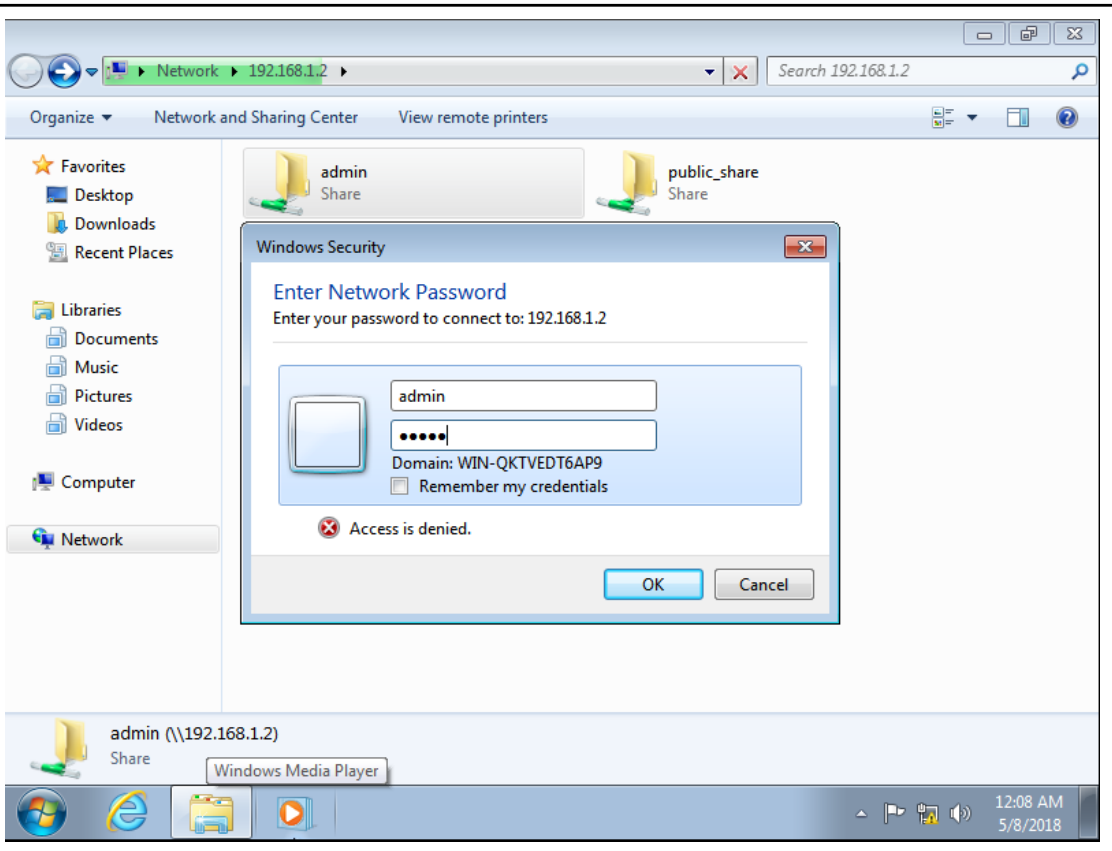

If user clicked admin, automatic access denied.

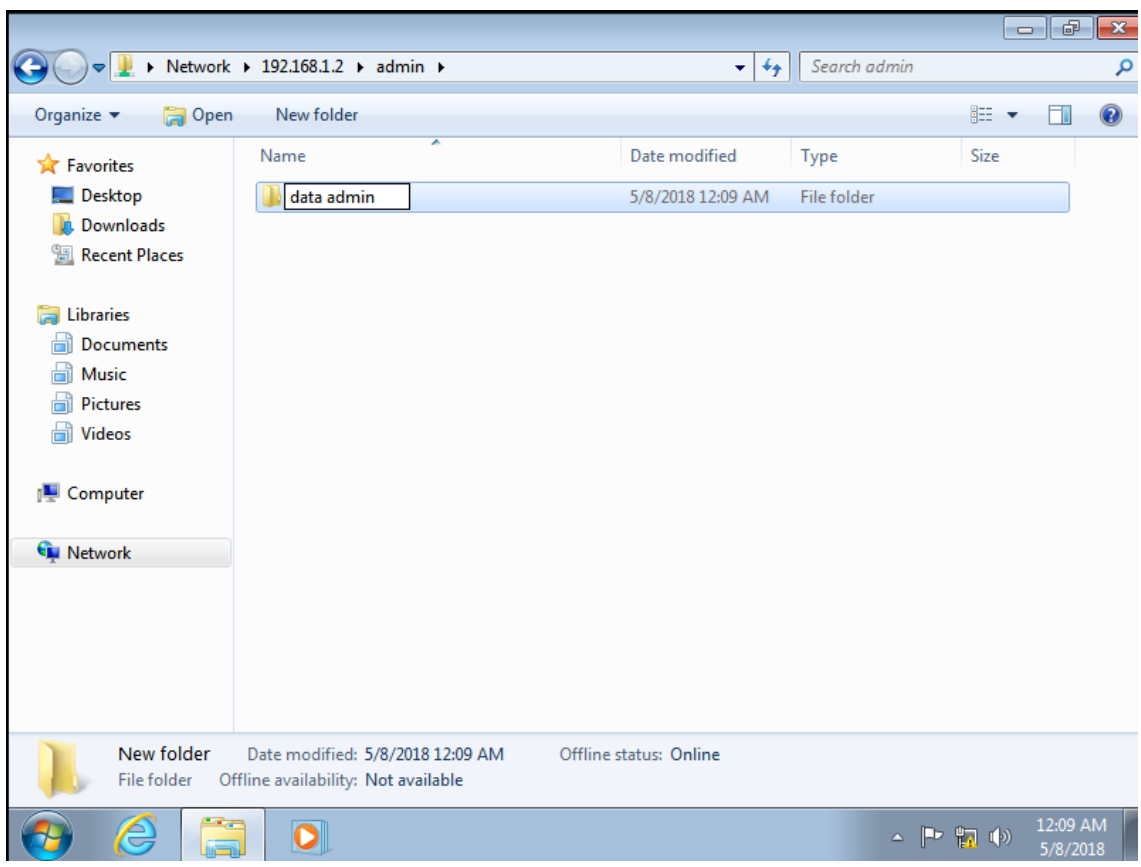

Make a folder data admin in admin file sharing 


\section{STEP-STEP CONFIGURATION SAMBA SERVER FILE SHARING}

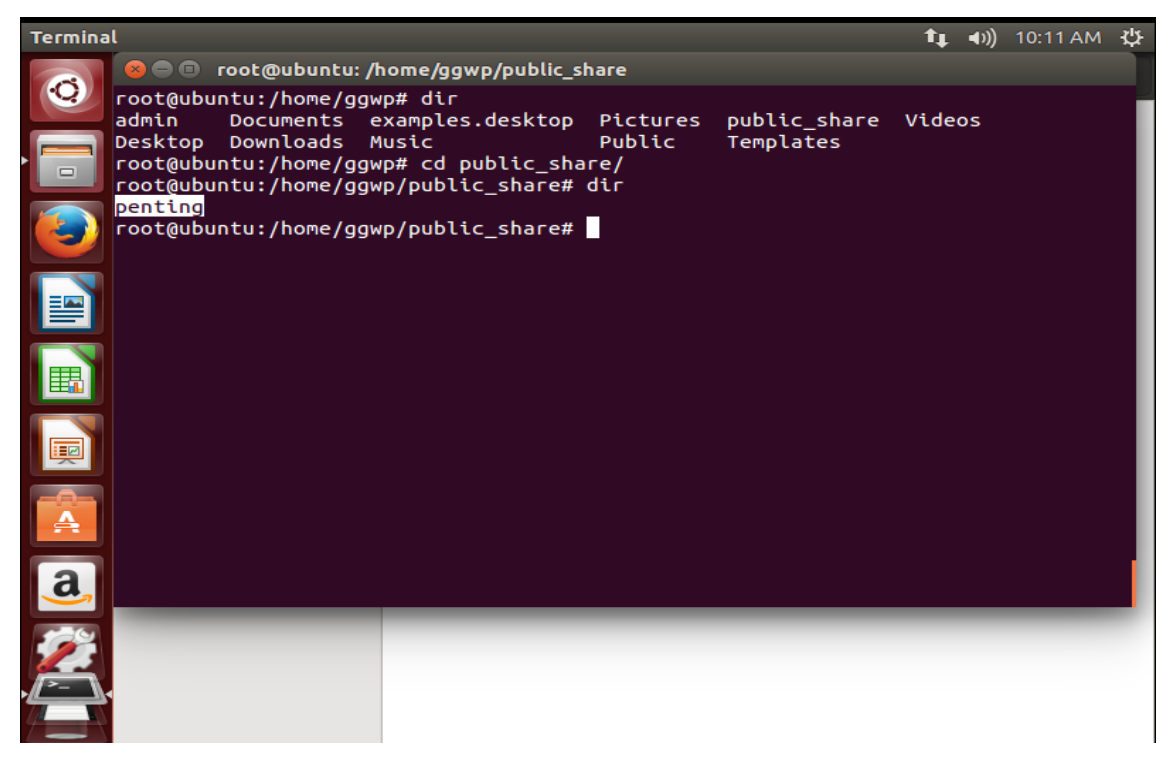

Folder penting has been exiest

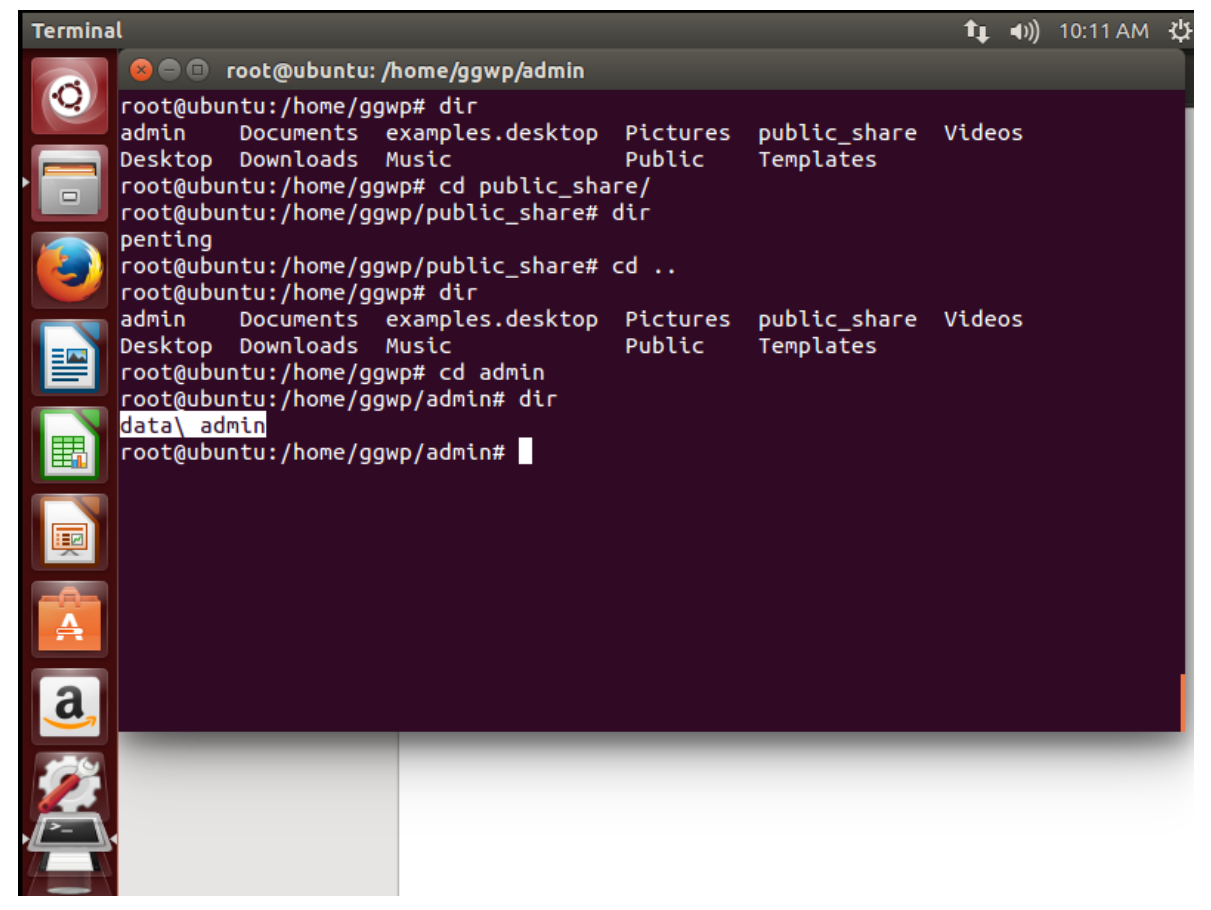

Folder data admin has been exiest 


\section{SYSTEM CONFIGURATION}

Hardware : : Intel ${ }^{R}$ Core ${ }^{\mathrm{TM}}$ i7-6700HQ CPU @ 2,60GHz 2,60 GHz, 4.00GB RAM, 1T HDD, DVD Super Multi DL drive, Asus ROG GL522VW

Operating System ： Windows 7, Ubuntu

Software $\quad$ : VMware Workstasion Pro

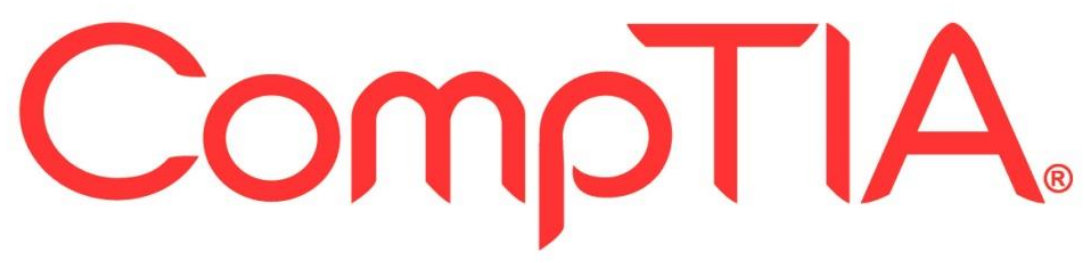




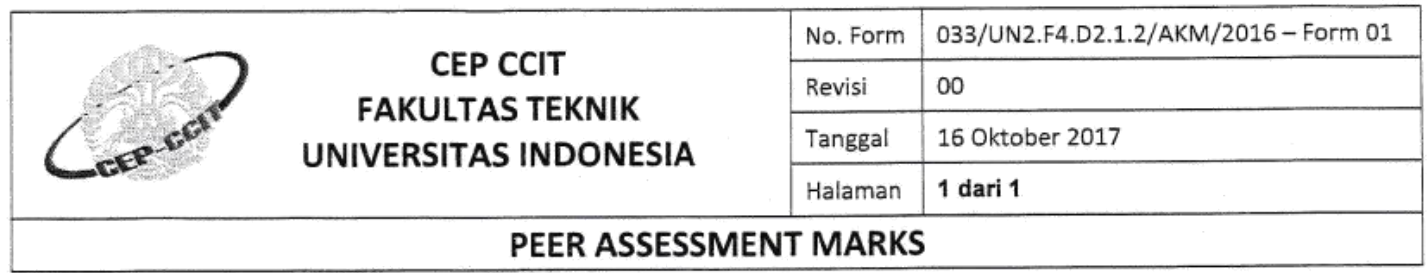

Group Number $\quad: \ldots . .$.

Presentation Test Type : ISAS/Project/.........

Date

Time

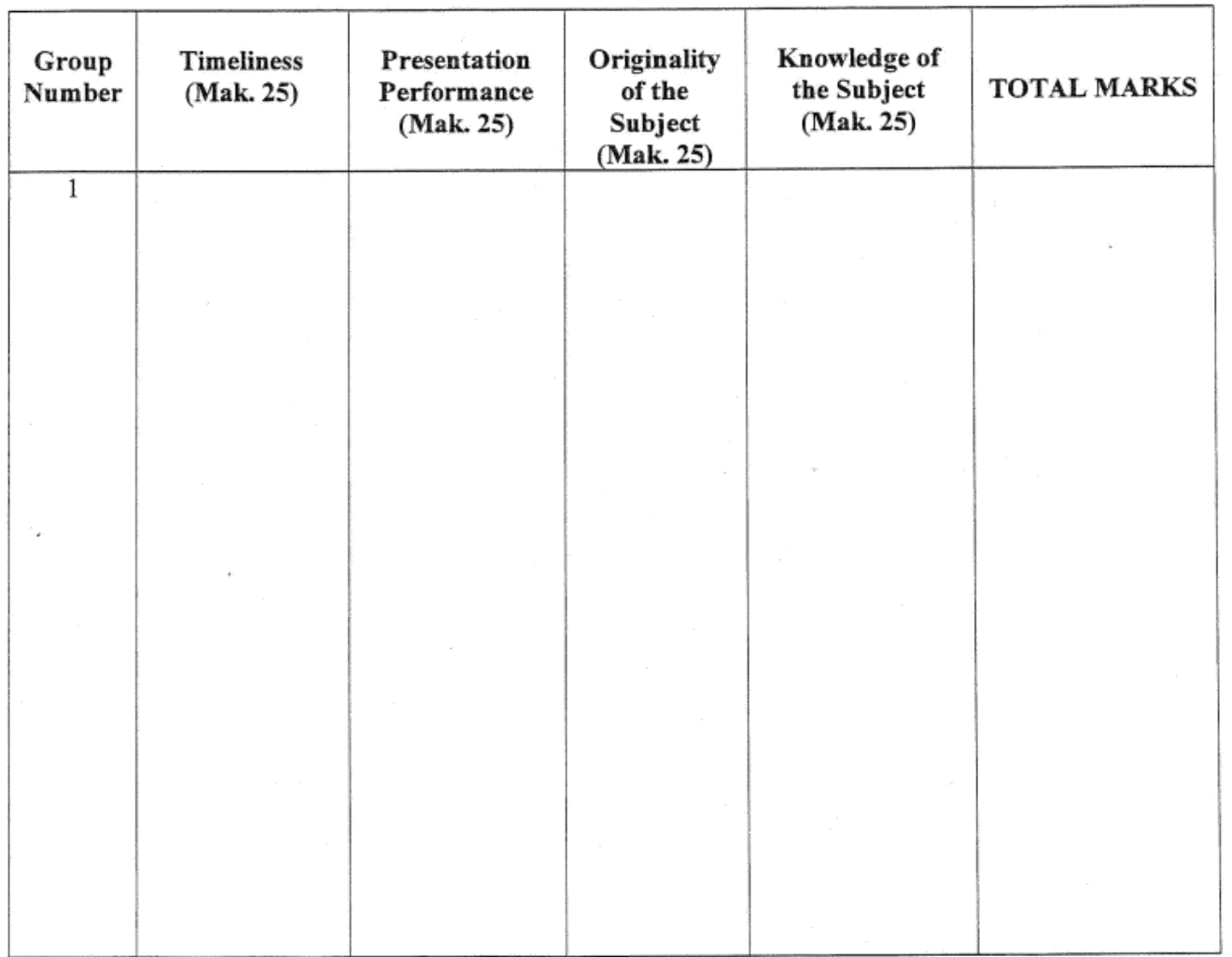

- Timeliness will be calculates by time of attending the presentation

- Presentation Performance will be assessed from the ability of groups when presenting the subject and handling questions from the audience.

- Originality of the subject will be marked based on the ideas of the ISAS/Project/other

- Knowledge of the Subject means how good the group mastering the topicafter working on the ISAS/Project/other

Assessor :
Group Number
Group Member

4 
